\title{
Análise florística e estrutural do componente arbustivo-arbóreo de uma floresta de galeria no Município de Cristais Paulista, SP, Brasil
}

\author{
Aloysio de Pádua Teixeira ${ }^{1,3}$ e Ricardo Ribeiro Rodrigues ${ }^{2}$
}

Recebido em 4/07/2005. Aceito em 27/04/2006

RESUMO - (Análise florística e estrutural do componente arbustivo-arbóreo de uma floresta de galeria no Município de Cristais Paulista, SP, Brasil). Remanescentes florestais na porção nordeste do Estado de São Paulo são ainda pouco estudados quanto à composição florística. Foi realizado o levantamento florístico e fitossociológico de uma floresta de galeria no Município de Cristais Paulista visando à caracterização da flora do remanescente e o estudo das relações florísticas com outras formações ribeirinhas. Para o levantamento fitossociológico foi utilizado o método de ponto-quadrante. Em quatro transeções paralelas ao curso d'água, foram estabelecidos 90 pontos eqüidistantes em 10 metros e amostrados os indivíduos com PAP $\geq 15 \mathrm{~cm}$. Espécies em estágio reprodutivo, não amostradas no levantamento fitossociológico, foram coletadas e identificadas. Foram encontradas 68 espécies, distribuídas em 37 famílias, das quais 53 espécies e 34 famílias foram amostradas no levantamento fitossociológico. O índice de diversidade (H’) para as espécies foi de 3,17 nats indivíduo ${ }^{-1}$ e as espécies mais importantes (em VI) foram Virola sebifera, Protium heptaphyllum, Tapirira guianensis e Copaifera langsdorffii. A comparação com outras florestas ribeirinhas evidenciou uma maior semelhança florística com as florestas situadas principalmente na bacia do Rio Grande, possivelmente devido às condições semelhantes de clima, e no Brasil Central, devido à rede de drenagem que atua como rota migratória das espécies. Foram encontradas também muitas espécies compartilhadas com os cerrados, evidenciando a contribuição da flora desse domínio para a floresta de galeria estudada.

Palavras-chave: Cerrado, diversidade de espécies, florestas ribeirinhas, similaridade florística

\begin{abstract}
Floristic and phytosociological analysis of the shrub/tree stratum in a gallery forest in Cristais Paulista, São Paulo State, Brazil). The floristic composition of forest remnants in northeastern São Paulo, Brazil, is still poorly reported. A floristic and phytosociological survey of a gallery forest in Cristais Paulista Municipality was carried out to characterize the flora and compare it to other riverine forests. The phytosociological aspects of the remnant were obtained by the point-centered quarter technique in four transects running parallel to the river bed, considering 90 points, equidistant ten meters, and sampling all individuals with pbh $\geq 15 \mathrm{~cm}$. All fertile specimens not included in the phytosociological sample were also identified. A total of 68 species and 37 families were found, with 53 species and 34 families reported in the phytosociological survey. The species diversity index ( $\left.\mathrm{H}^{\prime}\right)$ was 3.17 nats individual ${ }^{-1}$ and the most important species (IV) were Virola sebifera, Protium heptaphyllum, Tapirira guianensis and Copaifera langsdorffii. Comparison to other riverine forests showed greater floristic similarity with those found throughout the Rio Grande basin, possibly because of similar climates, and with forest remnants throughout Central Brazil due to the drainage network that provides a migratory route for the plant species. Many "cerrado" (Brazilian savanna) species were found in the gallery forest and this fact reinforces the role played by Brazilian savanna vegetation in the biodiversity of gallery forests.
\end{abstract}

Key words: Cerrado (Brazilian savanna), species diversity, riparian forests, floristic similarity

\section{Introdução}

A Província Biogeográfica do Cerrado cobria originalmente cerca de $23 \%$ do território brasileiro, ou aproximadamente dois milhões de $\mathrm{km}^{2}$, abrangendo os Estados de Goiás, Tocantins, Mato Grosso, Mato Grosso do Sul, Bahia, Minas Gerais, Ceará, Maranhão, Piauí, Rondônia, São Paulo e Paraná, além de algumas áreas disjuntas do Amapá, Amazonas, Pará e Roraima
(Ribeiro \& Walter 1998). No início do século vinte, a vegetação de cerrado ocupava cerca de $14 \%$ do Estado de São Paulo e, em função da expansão agrícola, da implantação de Pinus, Eucalyptus, Citrus e da introdução de gramíneas africanas para pastagens, o cerrado ocupa hoje menos de $1 \%$ do território paulista (Durigan et al. 2003).

Nas áreas de Cerrado, diferentes formas de vegetação, variáveis em fisionomia, estrutura e

\footnotetext{
1 Universidade Estadual Paulista, Departamento de Botânica, 3506-900 Rio Claro, SP, Brasil

2 Escola Superior de Agricultura "Luiz de Queiroz", Departamento de Ciências Biológicas, 13418-900 Piracicaba, SP, Brasil

3 Autor para correspondência: aloysioteixeira@yahoo.com.br
} 
composição florística, podem ser encontradas, em função de características edáficas, da frequiência e da intensidade de queimadas e de interferências antrópicas (Eiten 1990; Ribeiro \& Walter 1998; Ruggiero et al. 2002). Na província do Cerrado, sobre solos úmidos ou alagáveis, decorrentes da presença de cursos de água, de afloramento do lençol freático ou ainda do acúmulo de água em depressões, estabelecem-se comunidades de caráter florestal, como as florestas de galeria e as florestas paludosas, de caráter campestre, como os campos úmidos ou de caráter misto, como as veredas (Oliveira Filho et al. 1990; Ribeiro \& Walter 1998; Araújo et al. 2002). Essas formações, apesar de cobrirem apenas $5 \%$ da área abrangida pelo Cerrado (Marimon et al. 2002), mostram-se bastante heterogêneas, tanto em curtas distâncias, em função de diferenças topográficas e do regime de inundação, quanto entre regiões distintas, em função de condicionantes geológicos, pedológicos e climáticos (Oliveira Filho 1989; Ab'Sáber 2000).

Em função da ocupação de trechos estritamente associados aos cursos d'água do Cerrado, as florestas de galeria apresentam-se bastante vulneráveis a interferências antrópicas, que colocam em risco seu potencial para o fornecimento de alimentos e refúgio da fauna, além da conservação dos recursos hídricos (Oliveira Filho 1989; Marimon et al. 2002). Floristicamente, essas florestas apresentam alta diversidade de espécies, muitas delas compartilhadas com as florestas pluviais atlântica e amazônica e com o cerrado. Os laços florísticos entre as florestas de galeria e as florestas pluviais são decorrentes da maior umidade nos solos de fundos de vale, que compensa a sazonalidade climática no Cerrado, enquanto as espécies arbóreas, principalmente de cerradão, ocorrem nas porções mais bem drenadas nas margens dos cursos d'água (Oliveira Filho \& Ratter 1995).

Em função da supressão acelerada da vegetação, novos estudos tornam-se necessários em relação à composição florística, estrutural e à distribuição das populações pelos remanescentes, principalmente nas porções regionais pouco estudadas. $\mathrm{O}$ conhecimento gerado tem subsidiado planos de conservação e de restauração da vegetação. No nordeste do Estado de São Paulo, apesar de haver caracterizações florísticas de remanescentes de cerrado (Araújo et al. 1999; Durigan et al. 2003; Teixeira et al. 2004), não há relatos de estudos florísticos e estruturais das florestas de galeria.

No presente estudo, foi realizado o levantamento florístico e estrutural do componente arbustivo-arbóreo de uma floresta de galeria localizada no Município de Cristais Paulista, no nordeste do Estado de São Paulo, visando à ampliação do conhecimento florístico dessa porção do Estado e à análise comparativa das relações florísticas do remanescente com outras florestas ribeirinhas situadas em diferentes porções do território nacional.

\section{Material e métodos}

Caracterização da área de estudo - A floresta de galeria estudada $\left(20^{\circ} 24^{\prime} 56^{\prime}\right.$ 'S, $4^{\circ} 24^{\prime} 50^{\prime \prime} \mathrm{W}$, ca. $990 \mathrm{~m}$ ) localiza-se no Município de Cristais Paulista, porção nordeste do Estado de São Paulo. A região está inserida no Planalto de Franca, entre as cotas de 950 e $1.050 \mathrm{~m}$ de altitude, com orientação no sentido sul-norte, abrangendo os Municípios de Franca, Cristais Paulista e Pedregulho. Esse Planalto constitui o primeiro dos grandes planaltos de reverso de cuesta interna, no nordeste do Estado, e apresenta topografia uniforme e suavemente ondulada, sobre a qual aparece o arenito Bauru "fácies" flúvio-lacustre, vindo logo abaixo o arenito Botucatu, de origem eólica, entremeado por derrames basálticos (Rinaldi 1982). O Latossolo Vermelho amarelo fase arenosa é o solo predominante, principalmente nas altitudes mais elevadas. Nas vertentes menos inclinadas ocorre a "terra roxa", originada da decomposição do basalto, e nas margens dos cursos d'água são observados solos hidromórficos.

O clima da região enquadra-se no tipo "Cwb" de Köppen (mesotérmico úmido de altitude), que é caracterizado por duas estações bem definidas, sendo uma seca, de abril a setembro, e outra chuvosa, de outubro a março. A precipitação média anual é de 1.400 a $1.500 \mathrm{~mm}$, com temperatura média do mês mais frio (julho) em torno de $17{ }^{\circ} \mathrm{C}$, e do mês mais quente (janeiro) de $22^{\circ} \mathrm{C}$. A cobertura vegetal primitiva da região constituía-se de campos limpos e cerrados, associados a florestas semidecíduas e ribeirinhas (Rinaldi 1982).

A floresta de galeria, com cerca de 7 ha, estende-se pelas margens de uma das nascentes do ribeirão dos Cristais. Esse ribeirão é afluente do ribeirão do Japão, que juntamente com o ribeirão Santana, são tributários do Rio do Carmo, que por sua vez, deságua no Rio Grande. No remanescente estudado, a água aflora e flui no fundo de um vale bastante encaixado, que ocupa uma estreita faixa (inferior a cinco metros de largura) onde o encharcamento do solo é permanente e o componente arbóreo é representado por muitos indivíduos de 
Myrsine guianensis e Tapirira guianensis, com altura inferior a $8 \mathrm{~m}$. Em direção às margens, as encostas iniciam-se com uma pequena declividade, que aumenta gradativamente e, depois, se acentua. Essas encostas encontram-se sob pressão por processos erosivos causados pelo pisoteio do gado e acelerados pela descarga de águas pluviais. A vegetação distribui-se pelas duas margens, estendendo-se paralelamente ao curso d'água em uma faixa marginal de até aproximadamente $40 \mathrm{~m}$.

Procedimento de campo e análise dos dados - Para a caracterização fitossociológica do componente arbustivo-arbóreo foi utilizado o método de pontoquadrante (Cottam \& Curtis 1956). Segundo Matteucci \& Colma (1982), esse método despende menos tempo de aplicação em campo, requer menor número de trabalhadores para a sua aplicação e não é necessário ajustar o tamanho da unidade amostral às condições particulares da vegetação. Foram distribuídos 90 pontos eqüidistantes em $10 \mathrm{~m}$, sobre quatro transeções paralelas ao curso d'água, sendo duas transeções na margem direita e duas na margem esquerda (dispostas a cinco e $25 \mathrm{~m}$ do curso d'água). Mesmo nas duas transeções próximas ao curso d'água, pequenas elevações topográficas (barrancos com até $1,5 \mathrm{~m}$ de altura) impossibilitam o encharcamento periódico do solo, de forma que, de modo geral, a vegetação está estabelecida sobre solos bem drenados, com lençol freático profundo.

No levantamento fitossociológico foram amostrados os indivíduos com PAP (Perímetro à Altura do Peito) maior ou igual a $15 \mathrm{~cm}$, que foram medidos (PAP e altura) e identificados por meio de comparação com materiais do Herbário Rioclarense (HRCB) e da Universidade Estadual de Campinas (UEC), além do auxílio de especialistas. O sistema de classificação adotado para a listagem dos táxons baseou-se em Cronquist (1988), com exceção da família Cyatheaceae. Visando ao complemento do levantamento florístico, foram feitas coletas de material reprodutivo de indivíduos não amostrados no levantamento fitossociológico. Os trabalhos de campo ocorreram nos anos de 2000 e 2001.

Como descritores fitossociológicos foram utilizados os valores de densidade absoluta e os relativos de dominância e freqüência; o índice de valor de importância (VI) (Matteucci \& Colma 1982); o índice de diversidade de Shannon \& Weaner (H'), considerando a base logarítmica natural; e a eqüabilidade de Pielou (J) (Brower \& Zar 1984). Os descritores foram calculados pelo programa Fitopac (Shepherd 1995).

A similaridade florística entre a floresta de galeria estudada e outros 23 fragmentos de florestas ribeirinhas (galerias e semidecíduas aluviais) foi avaliada pelo índice de similaridade de Sørensen (Müller-Dombois \& Ellenberg 1974). Esse número de trabalhos em florestas ribeirinhas está muito aquém da totalidade de trabalhos nessa formação, pois não é objetivo do estudo apresentar a flora completa das florestas ribeirinhas do Brasil, mas sim discutir algumas relações florísticas da floresta de galeria de Cristais Paulista com outras florestas ribeirinhas situadas em Estados próximos ao território paulista. Para a análise, foram utilizados trabalhos publicados, abrangendo diferentes porções geográficas do Brasil extra-Amazônico (Distrito Federal e Estados de Mato Grosso, São Paulo, Minas Gerais e Paraná), com situações distintas de altitude, bacias hidrográficas e domínio vegetacional (Fig. 1). As florestas paludosas não foram consideradas, visto que a saturação hídrica permanente do solo atua como um fator altamente seletivo de espécies, determinando, para essa formação, uma flora muito peculiar (Torres et al. 1994; Ivanauskas et al. 1997; Toniato et al. 1998; Teixeira \& Assis 2005).

\section{Resultados}

Os 360 indivíduos amostrados pertencem a 53 espécies e 32 famílias. A distância média entre os indivíduos foi de $2,37 \mathrm{~m}$, correspondendo a uma densidade total estimada em 1.774 indivíduos ha-1. A

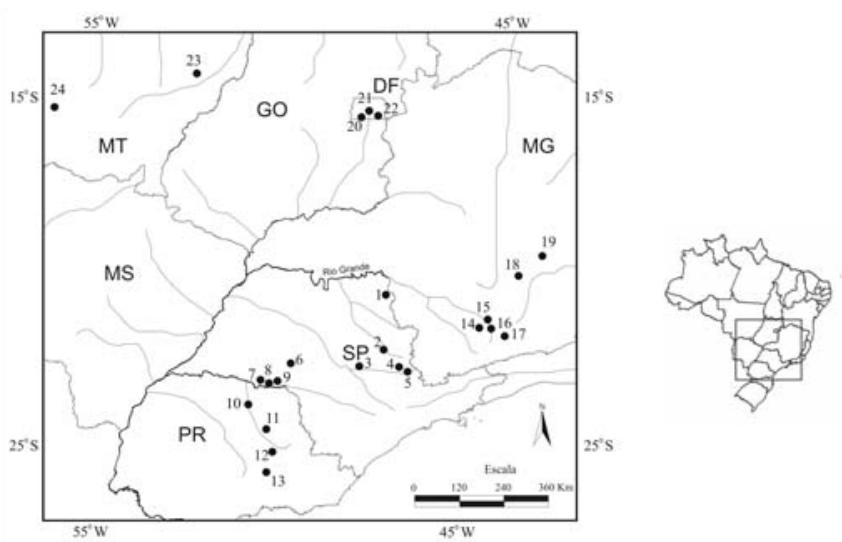

Figura 1. Localização das florestas ribeirinhas utilizadas na análise de similaridade florística com a floresta de galeria estudada no Município de Cristais Paulista, SP. A floresta de Cristais Paulista é representada pelo número 1 e as demais florestas são identificadas pela numeração (Código) da Tab. 3. 
área basal foi estimada em $27,8 \mathrm{~m}^{2} \mathrm{ha}^{-1}$. A diversidade de espécies ( $\left.\mathrm{H}^{\prime}\right)$ foi de 3,17 nats indivíduo ${ }^{-1}$ e o valor de eqüabilidade $(\mathrm{J})$ foi de 0,8 . Além das espécies amostradas nos quadrantes, foram acrescentadas 15 espécies pelas coletas casuais, totalizando 68 espécies, distribuídas em 37 famílias (Tab. 1).

As 10 espécies mais importantes no levantamento estrutural perfizeram cerca de $70 \%$ do VI e $68 \%$ dos indivíduos amostrados (Tab. 2). Virola sebifera, Protium heptaphyllum, Tapirira guianensis e Copaifera langsdorffii foram as espécies mais importantes na comunidade (em VI). A importância das três primeiras pode ser atribuída principalmente à alta densidade de indivíduos, enquanto C. langsdorffii destacou-se pelo valor de dominância relativa, sendo detentora do maior diâmetro amostrado $(64,3 \mathrm{~cm})$. $P$. heptaphyllum e $C$. langsdorffii foram as espécies representadas por indivíduos com as maiores alturas estimadas (18 e 17 m, respectivamente). Das espécies mais abundantes, as maiores médias de altura (superiores a $10 \mathrm{~m}$ ) foram constatadas para C. langsdorffii, Xylopia sericea, V. sebifera, Pera glabrata e Duguetia lanceolata, que se destacaram no dossel da floresta.

As famílias representadas por maior número de espécies foram Myrtaceae (oito espécies), Fabaceae e Lauraceae (cinco), Melastomataceae e Rubiaceae (quatro), Anacardiaceae e Annonaceae (três). Essas sete famílias representaram cerca de $47 \%$ das espécies amostradas. No levantamento estrutural, as quatro famílias com maior VI foram Myristicaceae (16,8\%), Anacardiaceae $(13,7 \%)$, Burseraceae $(13,3 \%)$ e Myrtaceae (9,2\%). Essas quatro famílias somaram cerca de $52 \%$ do VI e perfizeram $49 \%$ da densidade total, sendo que Myristicaceae e Burseraceae destacaram-se pela presença de uma só espécie, Virola sebifera e Protium heptaphyllum, respectivamente, principalmente em função do grande número de indivíduos dessas populações.

Os valores de similaridade florística entre a floresta estudada e os outros 23 remanescentes de florestas ribeirinhas variaram de $7,9 \%$ a $35,4 \%$ (Tab. 3). As maiores similaridades foram registradas com as florestas localizadas em Mogi-Guaçu, SP (Mata da Mariana), Itutinga, MG (Reservatório de Camargos), Madre de Deus de Minas, MG (Fazenda Patrimônio), Lavras, MG (Reserva Biológica de Poço Bonito), Brasília, DF (Mata do Taquara, na Reserva Ecológica do IBGE), Assis, SP (Estação Ecológica de Assis), Brasília, DF (Reserva Ecológica da Fazenda Água Limpa) e Bom Sucesso, MG (Fazenda Botelho). Os valores mais baixos foram observados em relação às florestas ribeirinhas situadas principalmente no Estado do Paraná (Municípios de Ipiranga, Tibagi, Sapopema e Ibiporã), além de florestas situadas no Município de Tarumã (oeste paulista). Das espécies encontradas no presente estudo, nenhuma delas ocorreu em todas as outras áreas estudadas, de forma que as mais freqüentes foram Casearia sylvestris e Copaifera langsdorffii (observadas em $83 \%$ dos trabalhos comparados), Tapirira guianensis (71\%), Cupania vernalis, Endlicheria paniculata e Luehea divaricata (67\%), Calophyllum brasiliense (62\%), Cecropia pachystachya (58\%), Protium heptaphyllum e Matayba elaegnoides (54\%), além de Amaioua guianensis (50\%).

\section{Discussão}

O número de espécies encontradas no presente estudo foi similar ao observado em algumas áreas, como Marília e Tarumã, ambas no oeste paulista, inferior ao observado em outras áreas, como Mogi-Guaçu (SP), Lavras (MG) e Brasília, e superior ao encontrado em Ipiranga (PR) e Assis (SP), entre outras. De modo geral, o número de espécies amostradas em florestas ribeirinhas de diferentes porções geográficas do Brasil tem se mostrado bastante variado, com registros desde cerca de 40 espécies arbustivo-arbóreas (Silva et al. 1992) até mais de 200 espécies (Oliveira Filho et al. 1994a; Carvalho et al. 1995). Essa grande amplitude é decorrente de diversas condições ambientais presentes nas zonas ribeirinhas (Dunn \& Stearns 1987; Naiman \& Décamps 1997), da matriz vegetacional circundante (Oliveira Filho et al. 1994b; Rodrigues \& Nave 2000), da dinâmica de clareiras naturais (Brandani et al. 1988), da interferência antrópica (Bertoni \& Martins 1987; Durigan \& Leitão Filho 1995) e dos diferentes métodos de amostragem empregados, como o esforço amostral (Magurram 1988; Melo et al. 2003) e o critério de inclusão dos indivíduos.

Diversos estudos têm demonstrado que existem diferenças florísticas e estruturais marcantes entre as florestas ribeirinhas estabelecidas sobre solos hidricamente saturados e solos bem drenados (Walter \& Ribeiro 1997; Ribeiro \& Walter 1998; Correia et al. 2001). As primeiras apresentam menor número de espécies (Silva et al. 1992) e grande prevalência de algumas populações higrófilas. De modo geral, o maior número de espécies tem sido observado nas florestas ribeirinhas cujas amostragens englobam esses 
Tabela 1. Espécies arbustivo-arbóreas (PAP $\geq 15 \mathrm{~cm}$ ) encontradas na floresta de galeria no Município de Cristais Paulista (SP). As famílias e espécies assinaladas com asterisco não foram amostradas no levantamento fitossociológico.

Famílias/Espécies

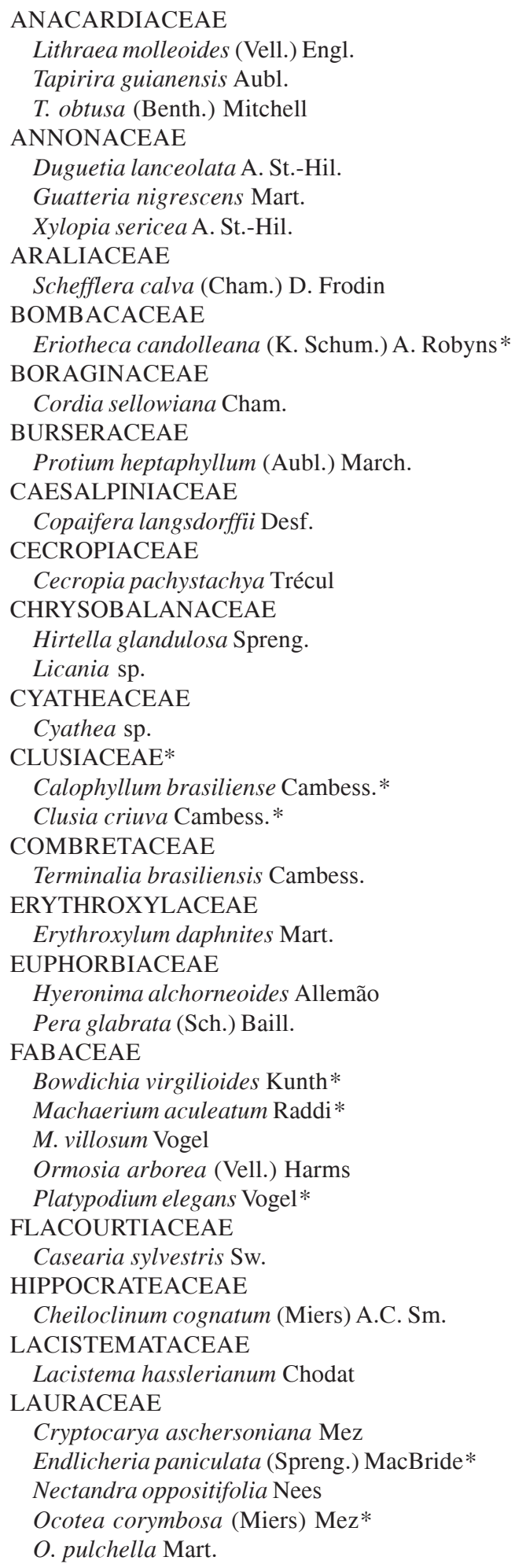

Famílias/Espécies

MALPIGHIACEAE

Byrsonima cf. intermedia A. Juss.

MELASTOMATACEAE

Miconia ligustroides (DC.) Naudin

Miconia sp. 1

Miconia sp. 2

Tibouchina granulosa*

MELIACEAE

Guarea guidonia (L.) Sleumer

MIMOSACEAE

Inga vera Will.

MONIMIACEAE

Siparuna guianenis Aubl.

Mollinedia sp.

MORACEAE

Brosimum glaziovii Taub.

MYRISTICACEAE

Virola sebifera Aubl.

MYRSINACEAE

Myrsine guianensis (Aubl.) Kuntze

MYRTACEAE

Campomanesia cf. guaviroba (DC.) Kiaersk.

Eugenia moraviana Berg*

Myrcia rostrata DC.

M. tomentosa DC.

Myrcia sp.

Myrciaria floribunda Berg*

Myrtaceae sp.1

Myrtaceae sp.2

OCHNACEAE

Ouratea castanaefolia (St.-Hil.) Engl.

Ouratea sp.

RUBIACEAE

Alibertia concolor (Cham.) K. Schum.

Alibertia sp.

Amaioua guianensis Aubl.

Coutarea hexandra (Jacq.) Schum.

SAPINDACEAE

Cupania vernalis Cambess.

Matayba elaeagnoides Radlk.*

STYRACACEAE

Styrax camporum Pohl

THYMELAEACEAE

Daphnopsis fasciculata (Meisn.) Nevl.*

TILIACEAE

Luehea divaricata Mart. \& Zucc.*

VERBENACEAE

Vitex polygama Cham.

VOCHYSIACEAE

Vochysia tucanorum Mart.

WINTERACEAE

Drymis brasiliensis Miers* 
Tabela 2. Espécies arbustivo-arbóreas (PAP $\geq 15 \mathrm{~cm}$ ) amostradas na floresta de galeria no Município de Cristais Paulista (SP). NI = número de indivíduos; DoR = dominância relativa; $\mathrm{FR}=$ freqüência relativa; $\mathrm{VI}=$ valor de importância; $\mathrm{Hmx}=$ altura máxima $(\mathrm{m}) ; \mathrm{Hmd}=$ altura média $(\mathrm{m}) ; \mathrm{Dmx}=$ diâmetro máximo $(\mathrm{cm}) ; \mathrm{Dmd}=$ diâmetro médio $(\mathrm{cm})$.

\begin{tabular}{|c|c|c|c|c|c|c|c|c|}
\hline Espécies & NI & DoR & FR & VI & Hmx & Hmd & Dmx & Dmd \\
\hline Virola sebifera & 54 & 21,24 & 13,65 & 16,63 & 15,5 & 10,5 & 46,2 & 15,1 \\
\hline Protium heptaphyllum & 46 & 13,21 & 10,48 & 12,15 & 18,0 & 9,7 & 26,9 & 12,7 \\
\hline Tapirira guianensis & 29 & 14,81 & 8,89 & 10,59 & 14,0 & 9,4 & 37,7 & 16,9 \\
\hline Copaifera langsdorffii & 14 & 10,86 & 4,44 & 6,40 & 17,0 & 10,8 & 64,3 & 19,1 \\
\hline Myrcia rostrata & 22 & 2,38 & 6,03 & 4,84 & 9,0 & 5,1 & 15,3 & 8,4 \\
\hline Pera glabrata & 18 & 5,23 & 4,13 & 4,79 & 14,0 & 10,3 & 29,0 & 13,1 \\
\hline Myrsine guianensis & 18 & 3,14 & 4,44 & 4,20 & 13,0 & 7,9 & 28,9 & 9,6 \\
\hline Siparuna guianenis & 19 & 1,20 & 5,40 & 3,96 & 10,0 & 6,6 & 17,2 & 6,2 \\
\hline Xylopia sericea & 12 & 3,37 & 3,17 & 3,29 & 15,0 & 10,7 & 22,6 & 13,1 \\
\hline Ocotea pulchella & 13 & 1,78 & 3,81 & 3,07 & 12,0 & 8,1 & 13,4 & 9,6 \\
\hline Tapirira obtusa & 4 & 6,39 & 1,27 & 2,92 & 15,0 & 12,3 & 54,4 & 29,1 \\
\hline Lacistema hasslerianum & 13 & 0,75 & 4,13 & 2,83 & 8,0 & 6,2 & 8,6 & 6,3 \\
\hline Duguetia lanceolata & 8 & 1,59 & 2,54 & 2,12 & 13,0 & 10,1 & 19,1 & 11,2 \\
\hline Myrcia tomentosa & 9 & 1,18 & 2,22 & 1,97 & 9,0 & 6,0 & 13,3 & 9,3 \\
\hline Guatteria nigrescens & 7 & 0,88 & 2,22 & 1,68 & 11,0 & 8,0 & 14,6 & 9,0 \\
\hline Erythroxylum daphnites & 6 & 1,33 & 1,90 & 1,63 & 9,0 & 5,8 & 23,5 & 11,2 \\
\hline Myrcia sp. & 7 & 0,42 & 2,22 & 1,53 & 10,0 & 8,0 & 8,3 & 6,5 \\
\hline Brosimum glaziovii & 6 & 0,45 & 1,90 & 1,34 & 9,5 & 6,8 & 9,9 & 7,1 \\
\hline Byrsonima cf. intermedia & 5 & 0,61 & 1,59 & 1,19 & 8,0 & 5,4 & 11,5 & 9,2 \\
\hline Cordia sellowiana & 4 & 1,20 & 1,27 & 1,19 & 13,0 & 8,5 & 24,8 & 12,7 \\
\hline Amaioua guianensis & 4 & 0,39 & 1,27 & 0,92 & 8,0 & 5,8 & 11,7 & 8,0 \\
\hline Myrtaceae sp.1 & 4 & 0,33 & 1,27 & 0,90 & 10,5 & 6,0 & 9,3 & 7,5 \\
\hline Ouratea castanaefolia & 3 & 0,55 & 0,95 & 0,78 & 8,5 & 6,5 & 16,2 & 10,5 \\
\hline Vochysia tucanorum & 2 & 1,00 & 0,63 & 0,73 & 11,5 & 9,8 & 22,0 & 18,6 \\
\hline Ouratea sp. & 2 & 0,32 & 0,63 & 0,50 & 4,0 & 3,5 & 11,5 & 10,7 \\
\hline Terminalia brasiliensis & 2 & 0,14 & 0,63 & 0,44 & 7,0 & 6,5 & 8,3 & 7,0 \\
\hline Ormosia arborea & 1 & 0,73 & 0,32 & 0,44 & 14,0 & 14,0 & 22,9 & 22,9 \\
\hline Cecropia pachystachya & 2 & 0,10 & 0,63 & 0,43 & 8,0 & 6,3 & 6,7 & 5,9 \\
\hline Cryptocarya aschersoniana & 1 & 0,65 & 0,32 & 0,42 & 14,0 & 14,0 & 21,6 & 21,6 \\
\hline Styrax camporum & 2 & 0,27 & 0,32 & 0,38 & 6,0 & 5,5 & 10,2 & 9,9 \\
\hline Hyeronima alchorneoides & 1 & 0,46 & 0,32 & 0,35 & 11,5 & 11,5 & 18,1 & 18,1 \\
\hline Vitex polygama & 1 & 0,33 & 0,32 & 0,31 & 5,5 & 5,5 & 15,4 & 15,4 \\
\hline Cheiloclinum cognatum & 1 & 0,33 & 0,32 & 0,31 & 8,5 & 8,5 & 15,3 & 15,3 \\
\hline Cyathea sp. & 1 & 0,27 & 0,32 & 0,29 & 5,0 & 5,0 & 14,0 & 14,0 \\
\hline Nectandra oppositifolia & 1 & 0,27 & 0,32 & 0,29 & 7,5 & 7,5 & 14,0 & 14,0 \\
\hline Campomanesia cf. guaviroba & 1 & 0,26 & 0,32 & 0,29 & 8,0 & 8,0 & 13,7 & 13,7 \\
\hline Licania sp. & 1 & 0,25 & 0,32 & 0,28 & 7,0 & 7,0 & 13,5 & 13,5 \\
\hline Miconia sp.1 & 1 & 0,18 & 0,32 & 0,26 & 8,5 & 8,5 & 11,5 & 11,5 \\
\hline Machaerium villosum & 1 & 0,16 & 0,32 & 0,25 & 4,0 & 4,0 & 10,8 & 10,8 \\
\hline Lithraea molleoides & 1 & 0,15 & 0,32 & 0,25 & 10,0 & 10,0 & 10,5 & 10,5 \\
\hline Cupania vernalis & 1 & 0,13 & 0,32 & 0,24 & 6,5 & 6,5 & 9,6 & 9,6 \\
\hline Inga vera & 1 & 0,11 & 0,32 & 0,24 & 6,5 & 6,5 & 8,9 & 8,9 \\
\hline Miconia ligustroides & 1 & 0,09 & 0,32 & 0,23 & 4,0 & 4,0 & 8,0 & 8,0 \\
\hline Hirtella glandulosa & 1 & 0,08 & 0,32 & 0,23 & 10,0 & 10,0 & 7,6 & 7,6 \\
\hline Myrtaceae sp.2 & 1 & 0,07 & 0,32 & 0,22 & 6,0 & 6,0 & 7,0 & 7,0 \\
\hline Casearia sylvestris & 1 & 0,06 & 0,32 & 0,22 & 4,0 & 4,0 & 6,7 & 6,7 \\
\hline Mollinedia sp. & 1 & 0,05 & 0,32 & 0,21 & 5,0 & 5,0 & 5,7 & 5,7 \\
\hline Coutarea hexandra & 1 & 0,05 & 0,32 & 0,21 & 7,0 & 7,0 & 5,7 & 5,7 \\
\hline Miconia sp.2 & 1 & 0,04 & 0,32 & 0,21 & 4,5 & 4,5 & 5,4 & 5,4 \\
\hline Guarea guidonia & 1 & 0,04 & 0,32 & 0,21 & 5,0 & 5,0 & 5,1 & 5,1 \\
\hline Alibertia sp. & 1 & 0,04 & 0,32 & 0,21 & 5,0 & 5,0 & 5,0 & 5,0 \\
\hline Alibertia concolor & 1 & 0,03 & 0,32 & 0,21 & 3,0 & 3,0 & 5,0 & 5,0 \\
\hline
\end{tabular}


Tabela 3. Similaridade florística entre a floresta de galeria estudada no Município de Cristais Paulista (SP) e outras 23 florestas ribeirinhas localizadas em diferentes porções geográficas do Brasil. As localidades estão listadas por ordem decrescente de ISS (índice de similaridade de Sørensen, em porcentagem). Cód. = código utilizado no mapa da Fig. 1; o clima corresponde à classificação de Köppen; NE = número de espécies; $\mathrm{NC}=$ número de espécies em comum com a floresta de galeria do Município de Cristais Paulista (SP); EE = Estação Ecológica; Faz. $=$ Fazenda RB $=$ Reserva Biológica RE $=$ Reserva Ecológica; $R E d=$ Reserva Estadual; $P E=$ Parque Estadual; EEp = Estação Experimental. $\mathrm{O}$ asterisco representa altitudes não fornecidas pelos autores.

\begin{tabular}{|c|c|c|c|c|c|c|c|}
\hline Localidades & ISS & Cód. & Altitude & Clima & NE & $\mathrm{NC}$ & Referências \\
\hline Mata da Mariana, EE Mogi-Guaçu (SP) & 35,4 & 4 & 900 & Cwa & 100 & 28 & Mantovani et al. (1989) \\
\hline Reservatório de Camargos, Itutinga (MG) & 29,1 & 16 & 920 & Cwb & 162 & 32 & $\begin{array}{l}\text { Van den Berg \& Oliveira Filho } \\
(2000)\end{array}$ \\
\hline Faz. Patrimônio, Madre de Deus de Minas (MG) & 26,0 & 17 & 925 & Cwb & 119 & 23 & Oliveira Filho et al. (1994b) \\
\hline RB Poço Bonito, Lavras (MG) & 25,3 & 14 & 1.075 & Cwb & 219 & 35 & Oliveira Filho et al. (1994a) \\
\hline RE IBGE, Brasília (DF) & 25,1 & 21 & 1.104 & Aw & 109 & 21 & Silva Júnior (2004) \\
\hline EE Assis (SP) & 24,8 & 9 & 500 & Cwa & 55 & 14 & Durigan \& Leitão Filho (1995) \\
\hline RE Faz. Água Limpa, Brasília (DF) & 24,6 & 20 & 1.100 & $\mathrm{Cw}$ & 80 & 17 & Felfili (1994) \\
\hline Faz. Botelho, Bom Sucesso (MG) & 23,8 & 15 & 825 & $\mathrm{Cwb}$ & 245 & 36 & Carvalho et al. (1995) \\
\hline RE Jardim Botânico de Brasília (DF) & 22,2 & 22 & 1.088 & Aw & 185 & 27 & Nóbrega et al. (2001) \\
\hline REd Porto Ferreira (SP) & 21,6 & 2 & 520 & Cwa & 81 & 15 & Bertoni \& Martins (1987) \\
\hline RE Mário Viana, Nova Xavantina (MT) & 21,3 & 23 & 250 & Aw & 120 & 19 & Marimon et al. (2002) \\
\hline Mata da Figueira, EE Mogi-Guaçu (SP) & 21,0 & 5 & $*$ & Cwa & 47 & 11 & $\begin{array}{l}\text { Gibbs \& Leitão Filho (1978), } \\
\text { Gibbs et al. (1980) }\end{array}$ \\
\hline Salgadeira, Cuiabá(MT) & 21,0 & 24 & 360 & Aw & 85 & 15 & Oliveira Filho (1989) \\
\hline PE Rola Moça, Belo Horizonte (MG) & 20,3 & 18 & $*$ & Cwa & 90 & 15 & Meyer et al. (2004) \\
\hline Faz. Santa Elisa, Brotas (SP) & 19,5 & 3 & 535 & Cwa & 106 & 16 & Salis et al. (1994) \\
\hline EEp Marília (SP) & 16,4 & 6 & 400 & Cwa & 64 & 10 & Durigan \& Leitão Filho (1995) \\
\hline Faz. Camarinha, Itambé do Mato Dentro (MG) & 16,1 & 19 & 620 & Cwa & 216 & 22 & Carvalho et al. (2000) \\
\hline Ipiranga (PR) & 12,8 & 13 & 806 & $\mathrm{Cfb}$ & 36 & 6 & Silva et al. (1992) \\
\hline Faz. Berrante, Tarumã (SP) & 12,7 & 8 & 520 & Cwa & 68 & 8 & Durigan \& Leitão Filho (1995) \\
\hline Faz. Batavo, Tibagi (PR) & 11,6 & 12 & 705 & $\mathrm{Cfa}$ & 115 & 10 & Dias et al. (1998) \\
\hline Faz. Bom Sucesso, Sapopema (PR) & 11,4 & 11 & 780 & $\mathrm{Cfa}$ & 118 & 10 & Silva et al.(1995) \\
\hline Faz. São Luís, Tarumã (SP) & 9,8 & 7 & 500 & Cwa & 64 & 6 & Durigan \& Leitão Filho (1995) \\
\hline Faz. Doralice, Ibiporã (PR) & 7,9 & 10 & 480 & $\mathrm{Cfa}$ & 93 & 6 & Soares-Silva et al. (1992) \\
\hline
\end{tabular}

diferentes grupos vegetacionais (Carvalho et al. 1995; 2000; Nóbrega et al. 2001; Marimon et al. 2002), que são resultantes das diferentes condições físicas atuantes no tempo e no espaço, tanto ao longo quanto perpendicularmente aos cursos d'água (Rodrigues 1992; Lima \& Zakia 2000). Da mesma forma, os índices de diversidade foram também muito variados, com valores desde 1,96 nats indivíduo ${ }^{-1}$, atribuído a uma floresta ribeirinha sobre solos hidricamente saturados no Município de Ipiranga, PR (Silva et al. 1992) até 4,45 nats indivíduo ${ }^{-1}$, calculado para uma floresta de galeria no Distrito Federal (Nóbrega et al. 2001).

Algumas espécies freqüentemente encontradas em solos hidromórficos, como Cecropia pachystachya, Guarea guidonia e Hyeronima alchorneoides, foram amostradas com baixa densidade de indivíduos, pois poucos pontos amostraram locais com solos hidricamente saturados. Outras espécies típicas de áreas com solos permanente ou periodicamente saturados, como Calophyllum brasiliense e Endlicheria paniculata (Oliveira Filho \& Ratter 1995) não foram amostradas no levantamento estrutural, embora tenham sido encontradas em alguns trechos no fundo do vale do remanescente estudado. Das espécies mais importantes no levantamento estrutural, Virola sebifera e Copaifera langsdorffii ocorrem preferencialmente em solos bem drenados de florestas de galeria, enquanto Tapirira guianensis e Protium heptaphyllum são muito freqüentes tanto em solos inundáveis quanto em solos bem drenados (Walter \& Ribeiro 1997).

A comparação da flora da floresta de galeria com as espécies encontradas em dois remanescentes de cerrado stricto sensu estudados na região, nos Municípios de Franca (Araújo et al. 1999) e Patrocínio Paulista (Teixeira et al. 2004), indica que 15 espécies ocorreram em comum com a primeira área e 17 com a segunda, sendo 12 espécies comuns às três áreas: Bowdichia virgilioides, Byrsonima intermedia, 
Copaifera langsdorffii, Miconia ligustroides, Myrcia rostrata, Myrsine guianensis, Ocotea corymbosa, O. pulchella, Siparuna guianenis, Styrax camporum, Tapirira guianensis, Virola sebifera e Xylopia sericea. As espécies em comum com os cerrados evidenciam a importante contribuição desse domínio vegetacional circundante para a flora da floresta de galeria estudada e corrobora as observações de Oliveira Filho \& Ratter (1995) de que muitas espécies generalistas são compartilhadas por florestas de galeria e cerrados. Essa flora compartilhada é atribuída ao fato de que a umidade do solo nas bordas das matas de galeria é relativamente mais baixa do que no interior, o que propicia uma transição para florestas secas, sendo o cerradão a principal formação observada nessas bordas (Oliveira Filho \& Ratter 1995).

Além da influência do cerrado sobre a flora da floresta de galeria estudada, a análise de similaridade florística demonstrou uma maior semelhança dessa floresta com as florestas ribeirinhas situadas nas cotas mais altas de altitude (acima de $825 \mathrm{~m}$ ), principalmente no sul de Minas Gerais (florestas semidecíduas aluviais), na região do alto Rio Grande, e, secundariamente, com aquelas situadas no Distrito Federal (florestas de galeria). As maiores semelhanças com as florestas ribeirinhas de Minas Gerais podem ser atribuídas à proximidade geográfica, à inserção das florestas na mesma bacia hidrográfica (Rio Grande) e aos valores altitudinais próximos, que condicionariam climas semelhantes. Da mesma forma, Van den Berg \& Oliveira Filho (2000) observaram grandes semelhanças florísticas entre as florestas do alto Rio Grande, Minas Gerais, sejam ribeirinhas (aluviais e galerias) ou semidecíduas montanas, em função da altitude e climas semelhantes da região em que se encontram, caracterizados por uma pronunciada estacionalidade climática. Coutarea hexandra, Daphnopsis fasciculata, Duguetia lanceolata, Eriotheca candolleana, Guateria nigrescens, Luehea divaricata, Machaerium aculeatum, M. villosum, Matayba elaeagnoides, Nectandra oppositifolia, Ocotea pulchella e Ormosia arborea foram compartilhadas apenas com as florestas estudadas nos Estados de São Paulo e Minas Gerais. Essas espécies são também encontradas com freqüência nas florestas semidecíduas montanas (sem influência aluvial) do sudeste do Brasil (Meira Neto et al. 1989; Oliveira Filho \& Machado 1993; EspíritoSanto et al. 2002) e evidenciam os laços florísticos entre a floresta de galeria estudada e as florestas semidecíduas da Província Paranaense.

Já as semelhanças florísticas observadas com as florestas de galeria do Distrito Federal podem ser decorrentes da influência da vegetação circundante, ou seja, domínio dos cerrados tanto na região de Cristais Paulista quanto no Brasil central e da rede de drenagem que atuaria como rota migratória das espécies ao longo da Província do Cerrado. Erythroxylum daphnites, Hirtella glandulosa, Ouratea castanaefolia, Virola sebifera e Xylopia sericea têm sido observadas principalmente nas matas de galeria do Brasil Central (Silva Júnior et al. 2001). Cheiloclinum cognatum e Hirtella glandulosa são também associadas às florestas de galeria do sul e sudeste da Província do Cerrado (Oliveira Filho \& Ratter 1995).

As maiores dissimilaridades florísticas com as florestas ribeirinhas localizadas no Estado do Paraná (Municípios de Ipiranga, Tibagi, Sapopema e Ibiporã) podem ser atribuídas às distintas condições climáticas do Estado em relação à área estudada. No Paraná, caracterizado pelo clima subtropical úmido, as florestas interioranas estão sujeitas a geadas severas freqüentes e não há uma estação seca definida (Silva et al. 1992), como na região sudeste e centro-oeste. As outras florestas que se mostraram com baixos valores de similaridade florística com a floresta de Cristais Paulista foram aquelas localizadas no oeste paulista, no Município de Tarumã. Essas florestas estão inseridas em fragmentos de floresta semidecídua submontana, com altitudes de 500 e 520 m (Durigan \& Leitão Filho 1995). As florestas submontanas do interior paulista estão localizadas principalmente nas porções oeste e central do Estado e apresentam composição florística distinta das florestas semidecíduas montanas, em função do clima mais quente, seco e sazonal (Salis et al. 1995), de forma que as condições climáticas parecem ser responsáveis pelas dissimilaridades observadas. Embora localizada muito próxima ao Município de Tarumã, com clima e altitude semelhantes, a floresta ribeirinha situada em Assis apresentou elevada similaridade florística com a floresta estudada. A floresta de Assis está inserida em um remanescente de cerradão (Durigan \& Leitão Filho 1995), o que reforça a importante contribuição da matriz vegetacional circundante para a flora das florestas ribeirinhas.

As espécies que ocorreram com maior freqüência nos 24 estudos (Casearia sylvestris, Copaifera langsdorffii, Tapirira guianensis, Cupania vernalis, Endlicheria paniculata, Luehea divaricata, Calophyllum brasiliense, Cecropia pachystachya, 
Protium heptaphyllum, Matyba elaegnoides e Amaioua guianensis) corroboram a observação de Rodrigues \& Nave (2000) em relação às espécies de ampla ocorrência nas florestas ribeirinhas do Brasil Extra-Amazônico, visto que apenas A. guianensis não foi citada pelos autores.

Com relação às famílias, a relação daquelas com maior riqueza específica para a floresta de galeria estudada (Myrtaceae, Fabaceae, Lauraceae, Rubiaceae, Anacardiaceae, Annonaceae e Melastomataceae) é compatível com o observado para as florestas ribeirinhas e semidecíduas do Estado de São Paulo (Leitão Filho 1982). Entretanto, estruturalmente, são observadas diferenças pronunciadas entre essas formações, principalmente em função da densidade de indivíduos representantes das famílias (Walter \& Ribeiro 1997).

O levantamento florístico realizado no remanescente de floresta de galeria da microbacia do ribeirão dos Cristais evidencia, para esta área de estudo, uma heterogeneidade florística composta por espécies que ocorrem em diferentes formações vegetacionais, como cerrados, florestas semidecíduas da Província Paranaense e florestas de galeria do Brasil Central. Essa heterogeneidade florística é atribuída à topografia, que determina a ocorrência de solos bem drenados e o estabelecimento de espécies preferenciais desses solos, principalmente elementos de ampla ocorrência nos cerrados, predominantes na região; ao clima, característico de altitudes mais elevadas, que determina a ocorrência de espécies de florestas semidecíduas montanas de ampla ocorrência na bacia do Rio Grande; e a rede de drenagem, que atua como rota migratória das espécies freqüentemente observadas nas florestas de galeria do Brasil Central. Por fim, ressalta-se a importância de outros estudos florísticos na porção nordeste do Estado de São Paulo, com o intuito de ampliar o conhecimento florístico das formações vegetacionais remanescentes, necessário para orientar planos de conservação da biodiversidade e a escolha de espécies para restauração florestal de trechos desprovidos de vegetação, como em Áreas de Preservação Permanente.

\section{Agradecimentos}

Agradecemos à Prefeitura Municipal de Cristais Paulista e ao Jardim Zoobotânico de Franca, pelo apoio logístico; Alba R.B. Araújo, Fabiano T. Farah, João Semir, Jorge Y. Tamashiro, Maria Inez J.G. Teixeira e Valnice T. Rampim, pelo auxílio na identificação das espécies; Alexandre C. Oliveira, Kelly Y.M. de
Almeida, Robson L. Capretz e Simone de P. Teixeira, pela ajuda nos trabalhos de campo; Marco A. Assis, Ricardo Viani, Rodrigo A.S. Pereira e assessores anônimos, pelas sugestões no manuscrito; Fernando Santiago e Reinaldo Monteiro, pela revisão de inglês; Thiago S. de Azevedo, pela ajuda na confecção do mapa.

\section{Referências bibliográficas}

Ab'Saber, A.N. 2000. O suporte geoecológico das florestas beiradeiras (ciliares). Pp. 15-25. In: R.R. Rodrigues \& H.F. Leitão Filho (eds.). Matas ciliares: conservação e recuperação. São Paulo, Edusp, Fapesp.

Araújo, A.R.; Teixeira, M.I.J.G. \& Rodrigues, R.R. 1999. Florística e fitossociologia de um trecho de cerrado no Município de Franca-SP. Naturalia 24: 153-170.

Araújo, G.M.; Barbosa, A.A.A.; Arantes, A.A. \& Amaral, A.F. 2002. Composição florística de veredas no Município de Uberlândia, M.G. Revista Brasileira de Botânica 25(4): 475-493.

Bertoni, J.E.A. \& Martins, F.R. 1987. Composição florística de uma floresta ripária na Reserva Estadual de Porto Ferreira, SP. Acta Botanica Brasilica 1(1): 17-26.

Brandani, A.; Hartshorn, G.S. \& Orians, G.H. 1988. Internal heterogeneity of gaps and species richness in Costa Rica tropical wet forest. Journal of Tropical Ecology 4: 99-119.

Brower, J.E. \& Zar, J.H. 1984. Field and laboratory methods for general ecology. Dubuque, Wm. C. Brown.

Carvalho, D.A.; Oliveira Filho, A.T.; Vilela, E.A. \& Gavilanes, M.L. 1995. Flora arbustivo-arbórea de uma floresta ripária no alto Rio Grande em Bom Sucesso, MG. Acta Botanica Brasilica 9(2): 231-245.

Carvalho, D.A.; Oliveira Filho, A.T.; Vilela, E.A. \& Curi, N. 2000. Florística e estrutura da vegetação arbórea de um fragmento de floresta estacional às margens do reservatório da Usina Hidrelétrica Dona Rita (Itambé do Mato Dentro, MG). Acta Botanica Brasilica 14(1): 37-55.

Correia, J.R.; Haridasan, M.; Reatto, A.; Martins, E.S. \& Walter, B.M.T. 2001. Influência dos fatores edáficos na distribuição de espécies arbóreas em matas de galeria na região do cerrado: uma revisão. Pp. 51-76. In: J.F. Ribeiro; C.E.L. Fonseca \& J.C. Souza-Silva (eds.). Cerrado: caracterização e recuperação de matas de galeria. Planaltina, Embrapa.

Cottam, G. \& Curtis, J.T. 1956. The use of distance measures in phytosociological sampling. Ecology 37(3): 451-460.

Cronquist, A. 1988. The evolution and classification of flowering plants. New York, New York Botanical Garden.

Dias, M.C.; Vieira, A.O.S.; Nakajima, J.; Pimenta, J.A. \& Lobo, C. 1998. Composição florística e fitossociologia do componente arbóreo das florestas ciliares do Rio Iapó, na bacia do Rio Tibagi, Tibagi, Paraná. Revista Brasileira de Botânica 21(2): 183-195. 
Dunn, C.P. \& Stearns, F. 1987. A comparison of vegetation and soils in floodplain and basin forested wetlands of southeastern Wisconsin. American Midland Naturalist 118: $375-384$.

Durigan, G. \& Leitão Filho, H.F. 1995. Florística e fitossociologia de matas ciliares do oeste paulista. Revista do Instituto Florestal 7(2): 197-239.

Durigan, G.; Siqueira, M.F.; Franco, G.A.D.C.; Bridgewater, S. \& Ratter, J.A. 2003. The vegetation of priority areas for cerrado conservation in São Paulo State, Brazil. Edinburgh Journal of Botany 60(2): 217-241.

Eiten, G. 1990. Vegetação do Cerrado. Pp. 9-65. In: M.N. Pinto (coord.). Cerrado: caracterização, ocupação e perspectivas. Brasília, UnB, SEMATEC.

Espírito-Santo, F.D.B; Oliveira Filho, A.T.; Machado, E.L.M.; Souza, J.S.; Fontes, M.A.L. \& Marques, J.J.G.S.M. 2002. Variáveis ambientais e a distribuição de espécies arbóreas em um remanescente de floresta estacional semidecídua montana no Campus da Universidade Federal de Lavras, MG. Acta Botanica Brasilica 16(3): 331-356.

Felfili, J.M. 1994. Floristic composition and phytosociology of the gallery forest alongside the Gama stream in Brasília, DF, Brazil. Revista Brasileira de Botânica 17(1): 1-11.

Gibbs, P.E. \& Leitão Filho, H.F. 1978. Floristic composition of an area of gallery forest near Mogi Guaçu, State of São Paulo, Brazil. Revista Brasileira de Botânica 1: 151-56.

Gibbs, P.E.; Leitão Filho, H.F. \& Abbott, R.J. 1980. Application of the point-centred quarter method in a floristic survey of an area of gallery forest at Mogi Guaçu, SP. Revista Brasileira de Botânica 3: 17-22.

Ivanauskas, N.M.; Rodrigues, R.R. \& Nave, A.G. 1997. Aspectos ecológicos de uma mata de brejo em Itatinga, SP: florística, fitossociologia e seletividade de espécies. Revista Brasileira de Botânica 20(2): 139-153.

Leitão Filho, H.F. 1982. Aspectos taxonômicos das florestas do Estado de São Paulo. Silvicultura em São Paulo 16A: 197-206.

Lima, W.P. \& Zakia, M.J.B. 2000. Hidrologia de matas ciliares. Pp. 33-44. In: R.R. Rodrigues \& H.F. Leitão Filho (eds.). Matas ciliares: conservação e recuperação. São Paulo, Edusp, Fapesp.

Magurram, A.E. 1988. Ecological diversity and its measurement. Princeton, Princeton University.

Mantovani, W.; Rossi, L.; Neto, S.R.; Assad-Ludewigs, I.Y.; Wanderley, M.G.L.; Melo, M.M.R.F. \& Toledo, C.B. 1989. Estudo fitossociológico de áreas de mata ciliar em Mogi Guaçú, SP, Brasil. Pp. 235-267. In: L.M. Barbosa (coord.). Anais do I Simpósio sobre mata ciliar. Campinas, Fundação Cargill.

Marimon, B.S.; Felfilli, J.M. \& Lima, E.S. 2002. Floristic and phytossociology of the gallery forest of the Bacaba stream, Nova Xavantina, Mato Grosso, Brazil. Edinburgh Journal of Botany 59(2): 303-318.

Matteucci, S.D. \& Colma, A. 1982. Metodologia para el estudio de la vegetacion. Washington, Secretaria General de la Organización de los Estados Americanos.
Melo, A.S.; Pereira, R.A.S.; Santos, A.J.; Shepherd, G.J.; Machado, G.; Medeiros, H.F. \& Sawaya, R.J. 2003. Comparing species richness among assemblages using sample units: why not use extrapolation methods to standardize different sample sizes? Oikos 101(2): 398-410.

Meira Neto, J.A.A.; Bernacci, L.C.; Grombone, M.T.; Tamashiro, J.Y. \& Leitão Filho, H.F. 1989. Composição florística da floresta semidecídua de altitude do Parque Estadual da Grota Funda (Atibaia, Estado de São Paulo). Acta Botanica Brasilica 3(2): 51-75.

Meyer, S.T.; Silva, A.F.; Júnior, P.M. \& Meira Neto, J.A.A. 2004. Composição florística da vegetação arbórea de um trecho de floresta de galeria do Parque Estadual do Rola-Moça na região metropolitana de Belo Horizonte, MG, Brasil. Acta Botanica Brasilica 18(4): 701-709.

Müeller-Dombois, D. \& Ellenberg, H. 1974. Aims and methods for vegetation ecology. New York, J. Wiley and Sons.

Naiman, R.J. \& Décamps, H. 1997. The ecology of interfaces: riparian zones. Annual Review of Ecology and Systematics 28: 621-58.

Nóbrega, M.G.G.; Ramos, A.E. \& Silva Júnior, M.C. 2001. Composição florística e estrutura na mata de galeria Cabeça-de-Viado no Jardim Botânico de Brasília-DF. Boletim do Herbário Ezechias Paulo Heringer 8: 44-65.

Oliveira Filho, A.T. 1989. Composição florística e estrutura comunitária da floresta de galeria do córrego da Paciência, Cuiabá (MT). Acta Botanica Brasilica 3(1): 91-112.

Oliveira Filho, A.T.; Ratter, J.A. \& Shepherd, G.J. 1990. Floristic composition and community structure of a Brazilian gallery forest. Flora 184: 103-117.

Oliveira Filho, A.T. \& Machado, J.N.M. 1993. Composição florística de uma floresta semidecídua Montana, na Serra de São José, Tiradentes, Minas Gerais. Acta Botanica Brasilica 7(2): 71-88.

Oliveira Filho, A.T.; Almeida, R.J.; Mello, J.M. \& Gavilanes, M.L. 1994a. Estrutura fitossociológica e variáveis ambientais em um trecho de mata ciliar do córrego dos Vilas Boas, Reserva Biologia do Poço Bonito, Lavras (MG). Revista Brasileira de Botânica 17(1): 67-85.

Oliveira Filho, A.T.; Vilela, E.A.; Gavilanes, M.L. \& Carvalho, D.A. 1994b. Effect of flooding regime and understorey bamboos on the physiognomy and tree species composition of a tropical semideciduous forest in Southeastern Brazil. Vegetatio 113: 99-124.

Oliveira Filho, A.T. \& Ratter, J.A. 1995. A study of the origen of Central Brazilian forests by the analysis of plants species distribution patterns. Edinburgh Journal of Botany 52(2): 141-194.

Ribeiro, J.F. \& Walter, B.M.T. 1998. Fitofisionomias do Bioma Cerrado. Pp. 89-166. In: S.M. Sano \& S.P Almeida (eds.). Cerrado: ambiente e flora. Planaltina, Embrapa, CPAC.

Rinaldi, D.M.C. 1982. As boçorocas como condicionantes do crescimento urbano de Franca. São Paulo, SP. Dissertação de Mestrado. Universidade de São Paulo, São Paulo. 
Rodrigues, R.R. 1992. Análise de um remanescente de vegetação natural às margens do Rio Passa Cinco, Ipeúna, SP. Campinas, SP. Tese de Doutorado. Universidade Estadual de Campinas, Campinas.

Rodrigues, R.R. \& Nave, A.G. 2000. Heterogeneidade florística das matas ciliares. Pp. 45-71. In: R.R. Rodrigues \& H.F. Leitão Filho (eds.). Matas ciliares: conservação e recuperação. São Paulo, Edusp, Fapesp.

Ruggiero, P.G.C.; Batalha, M.A.; Pivello, V.R. \& Meirelles, S.T. 2002. Soil vegetation relationships in cerrado (Brazilian savanna) and semideciduous forest, Southeastern Brazil. Plant Ecology 160: 1-16.

Salis, S.M.; Tamashio, J.Y. \& Joly, C.A. 1994. Florística e fitossociologia do estrato arbóreo de um remanescente de mata ciliar do Rio Jacaré Pepira, Brotas, SP. Revista Brasileira de Botânica 17(2): 93-103.

Salis, S.M.; Shepherd, J.G. \& Joly, C.A. 1995. Floristic comparison of mesophytic semideciduous forests of the interior of the state of São Paulo, southeast Brazil. Vegetatio 119: 155-164.

Shepherd, G.J. 1995. Fitopac 1. Manual do usuário. Departamento de Botânica. Universidade Estadual de Campinas.

Silva, S.M.; Silva, F.C.; Vieira, A.O.S.; Nakajima, J; Pimenta, J.A. \& Colli, S. 1992. Composição florística e fitossociológica do componente arbóreo das florestas ciliares da bacia do Rio Tibagi: 2. várzea do Rio Bitumirim, Município de Ipiranga, PR. Revista do Instituto Florestal 5(1): 191-198.

Silva, F.C.; Fonseca, E.P.; Soares-Silva, L.H.; Muller, C. \& Bianchini, E. 1995. Composição florística e fitossociologia do componente arbóreo das florestas ciliares da bacia do Rio Tibagi. 3. Fazenda Bom Sucesso, Município de Sapopema, PR. Acta Botanica Brasilica 9(2): 289-302.

Silva Júnior, M.C.; Felfili, J.M.; Walter, B.M.T.; Nogueira, P.E.; Rezende, A.V.; Morais, R.O. \& Nóbrega, M.G.G. 2001. Análise da flora arbórea de matas de galeria do Distrito Federal: 21 levantamentos. Pp. 143-191. In: J.F. Ribeiro; C.E.L. Fonseca \& J.C. Souza-Silva (eds.). Cerrado: caracterização e recuperação de matas de galeria. Planaltina, Embrapa Cerrados.
Silva Júnior, M.C. 2004. Fitossociologia e estrutura diamétrica da mata de galeria do Taquara, na Reserva Biológica do IBGE, DF. Revista Árvore 28(3): 419-428.

Soares Silva, L.H.; Bianchini, E.; Fonseca, E.P.; Dias, M.C.; Medri, M.E. \& Zangaro Filho, W. 1992. Composição florística e fitossociológica do componente arbóreo das florestas ciliares da bacia do Rio Tibagi: 1. Fazenda Doralice, Ibiporã, PR. Revista do Instituto Florestal 5(1): 199-206.

Teixeira, A.P. \& Assis, M.A. 2005. Caracterização florística e fitossociológica do componente arbustivo-arbóreo de uma floresta paludosa no Município de Rio Claro (SP), Brasil. Revista Brasileira de Botânica 28(3): 467-476.

Teixeira, M.I.J.G.; Araújo, A.R.; Valeri, S.V. \& Rodrigues, R.R. 2004. Florística e fitossociologia de área de cerrado s.s. no Município de Patrocínio Paulista, nordeste do Estado de São Paulo. Bragantia 63(1): 1-11.

Toniato, M.T.Z.; Leitão Filho, H.F. \& Rodrigues, R.R. 1998. Fitossociologia de um remanescente de floresta higrófila (Mata de brejo) em Campinas, SP. Revista Brasileira de Botânica 21(2): 197-210.

Torres, R.B.; Matthes, L.A.F. \& Rodrigues, R.R. 1994. Florística e estrutura do componente arbóreo de mata de brejo em Campinas, SP. Revista Brasileira de Botânica 17(2): 189-194.

Van den Berg, E. \& Oliveira Filho, A.T. 2000. Composição florística e estrutura fitossociológica de uma floresta ripária em Itutinga, MG, e comparação com outras áreas. Revista Brasileira de Botânica 23(3): 231-253.

Walter, B.M.T. \& Ribeiro, J.F. 1997. Spatial floristic patterns in gallery forests in the cerrado region, Brazil. Pp. 339-349. In: J. Imanã-Encinas \& C. Kleinn (eds.). Proceedings of the International Symposium on assessment and monitoring of forests in tropical dry regions with special reference to gallery forests. Brasília, University of Brasília. 